\title{
La modernidad entumecida. Sobre la crítica de Adorno al serialismo
}

\author{
The numb modernity. About Adorno's critique of serialism
}

\author{
ESTEBAN ALEJANDRO JUÁREZ \\ SeCyT - Universidad Nacional de Córdoba (Argentina)
}

Recibido: 7-12-2011

Aprobado definitivamente: 7-2-2012

\section{RESUMEN}

El artículo se propone registrar los puntos principales de la controvertida relación que Theodor Adorno mantuvo, entre 1950 y 1966, con los jóvenes músicos reunidos en torno a los Cursos Internacionales para la Nueva Música realizados en Darmstadt. Se expondrá el modo en que en la música serial, a pesar de su progresismo, que el filósofo medía por el trato con la modernidad radical representada por la escuela vienesa de Schönberg, resonaban elementos que neutralizaban las fuerzas productivas de la nueva música. Al final se elucidará la justificación política que acompañaba a los síntomas estéticos de envejecimiento que Adorno atribuía al círculo de compositores de postguerra.

PALABRAS CLAVE

ADORNO, ESTÉTICA NEGATIVA, RACIONALIZACIÓN, ARTE AUTÓNOMO, MÚSICA SERIAL

\begin{abstract}
The paper proposes to record the main points of the controversial relationship Theodor Adorno held, between 1950 and 1966, with the young musicians gathered around the International Courses for the New Music performed in Darmstadt. Here is presented the way in which in serial music, despite its progressivism, which the philosopher measured in the treatment with the radical modernity represented by the Viennese School of Schönberg, resounded elements that neutralized the productive forces of the new music. Finally, I intend to elucidate the political justification that accompanied the aesthetics symptoms of aging that Adorno attributed to the circle of post-war composers.

KEYWORDS

ADORNO, NEGATIVE AESTHETICS, RATIONALIZATION, AUTONOMOUS

ART, SERIAL MUSIC
\end{abstract}




\section{ADORNO, ENTRE VIENA Y DARMSTADT}

THEODOR W. AdORNO PERMANECIÓ CONVENCIDO hasta su muerte de que, en su apogeo histórico, la atonalidad libre de Arnold Schönberg había resguardado, más que ninguna otra producción musical, una promesse du bonheur. Según el planteo adorniano, estas arduas composiciones del músico vienés habían alojado esa promesa, aunque lo habían hecho de un modo encriptado en el trato inmanente con las técnicas y materiales artísticos más avanzados de la época. Sólo desde su proceder autónomo, estas obras podían contrarrestar el peso de un mundo social en el cual la administración de las necesidades y los deseos de los hombres falseaba toda felicidad auténtica con satisfacciones sucedáneas. Pero también Adorno advertiría en ese comportamiento estético, en el que cifraba una felicidad no distorsionada, una praxis modélica de una correcta posición histórica del sujeto ante la objetividad social. ${ }^{1}$ Dicha praxis, al tiempo que se adecuaba a la idea de la obra de arte como un campo de fuerzas en tensión operantes en el interior de la composición misma, se insertaba en un horizonte de expectativas utópico. Pues, mediante la negación de toda apariencia de reconciliación entre sujeto y objeto en la inmanencia de la obra, en la nueva música instaurada por Schönberg traslucía, frente a la ilusión de la integración sin fisuras impuesta por la sociedad real, una imagen inaprensible de un estado sin dominio violento. Si bien Adorno no se desprendió nunca de la irradiación provocada por las perturbadoras tensiones contenidas en las piezas de aquel período de Schönberg, sin embargo ello no significó un reclamo por la restitución del paraíso perdido de la libre atonalidad. Por el contrario, muchos de sus más importantes escritos musicales elaborados tras el retorno del exilio americano se centraron en la situación de la música luego de los desarrollos atonales y dodecafónicos llevados a cabo por el vienés. Por ello, entre 1950 y 1966, las energías productivas de Adorno apuntaron al análisis crítico de las innovaciones serialistas de los jóvenes músicos agrupados en aquellos años en torno a los Cursos Internacionales de Verano de Nueva Música, celebrados en Kranichstein y Darmstadt.

En términos generales, lo que tomaría como criterio para evaluar a esas innovaciones era la concepción según la cual el arte más avanzado debía estar a la altura de las exigencias del presente. Según Adorno, estar a la altura del presente significaba que, en ese momento histórico, las obras individuales fueran capaces de extraer del estado alcanzado en la evolución del material musical las máximas consecuencias estéticas del proceso de declinación de la tonalidad iniciado por la Segunda Escuela de Viena. ${ }^{2}$ Por lo tanto, Adorno pensaba que las nuevas generaciones debían asumir y superar los problemas compositivos que sus antecesores habían planteado pero no resuelto. Al juzgar que los serialistas de la llamada Primera Escuela de Darmstadt no satisfacían esta exigencia, el filósofo no les daría el crédito teórico esperado. Esto trajo aparejado una profunda conmoción en el interior del movimiento serialista, ya que, como testimoniaría años más tarde Heinz-Klaus Metzger, ${ }^{3}$ sus mentores suponían que

\footnotetext{
${ }^{1}$ T. W. Adorno, «Sobre algunos trabajos de Arnold Schönberg», en Impromptus, Obra completa 17, tr. A. Gómez y A. Brotons. Madrid: Akal, 2008, pp. 353 ss. Cf. del mismo autor, «El compositor dialéctico», op cit., p. 214.

2 Para una clásica crítica de la tesis sostenida por Adorno de que los materiales artísticos que han alcanzado el mayor progreso histórico marcan el criterio de lo que es estéticamente posible y lo que no en el tiempo presente, $c f$. P. Bürger, «Das Altern der Moderne», en L. von Friedeburg y J. Habermas (eds.), Adorno-Konferenz 1983. Frankfurt am Main: Suhrkamp, 1983, p. 177 ss., y P. Bürger, Teoría de la vanguardia, tr. J. García. Barcelona: Península, 2000, pp. 123 ss.

${ }^{3}$ H.-K. Metzger, «Das Ende der Musikgeschichte», en J. Früchtl y M. Calloni (eds.), Geist gegen den Zeitgeist: Erinnern an Adorno. Frankfurt am Main: Suhrkamp, 1991, p. 165.
} 
concretaban de modo revolucionario los postulados teórico-musicales que Adorno había pergeñado en Filosofía de la nueva música y, por ende, aguardaban su completo apoyo.

Centrándose en la posición que a partir de 1950 adoptó Adorno en el choque con los jóvenes impulsores del serialismo congregados en Darmstadt y Kranichstein, el presente artículo se propone plasmar algunos de los episodios argumentativos más emblemáticos en la historia de este conflictivo cruce generacional. Se expondrán entonces las razones por las cuales el autor de Filosofía de la nueva música llegó a pensar que en los adeptos a la música serial resplandecían rasgos propiamente estéticos que entumecían las fuerzas productivas de la música más avanzada, a pesar de que en principio ellos contraían el mayor compromiso con las consecuencias de las experiencias de la modernidad radical representada por Schönberg, Alban Berg y Anton von Webern. Por último, con esta reconstrucción se desea llegar al enclave político que impulsaba a la reflexión de Adorno sobre los síntomas de envejecimiento que impregnaban al círculo de compositores de postguerra.

\section{LOS SÍNTOMAS DEL ESTANCAMIENTO}

Los cursos de verano de Darmstadt, que empezaron a gestarse en 1946 a partir de la iniciativa de Wolfgang Steinecke, se habían constituido ya en la década de 1950 en la principal usina para el despliegue de la música serial europea. ${ }^{4}$ Tal vez por los talentos convocados, por las radicales exploraciones musicales que allí se impulsaron y por el sorprendente modo en que estas exploraciones se enfrentaron al dictum de componer música después de Auschwitz, también en dichos cursos se fue fraguando el espacio propicio para el desarrollo de un intenso enfrentamiento generacional. Pues en ellos se pudo evidenciar la brecha histórica que separaba a la generación educada en la tradición de la Segunda Escuela de Viena, cuyo teórico más consistente era en ese momento Adorno, de aquel heterogéneo grupo que encarnaba, para el frankfurtiano, a la nueva música en su fase postschönberguiana.

La participación de Adorno como expositor y compositor en los seminarios de Darmstadt comenzó en $1950 .{ }^{5}$ Durante ese año dictó una serie de conferencias bajo el título Criterios de la nueva música. ${ }^{6} \mathrm{Al}$ año siguiente dirigió el Colectivo de trabajo para la composición libre, en donde se enfrentó por primera vez con una composición serial, la Sonata para dos pianos op. I de Karel Goeyvaerts, a la cual consideró despectivamente como «el más increíble de los galimatías». ${ }^{7}$ En este mismo período

\footnotetext{
${ }^{4}$ Una valiosa documentación sobre los cursos en Darmstadt se encuentra reunida en: H.-K. Metzger y R. Rainer (eds.), «Sonderband Darmstadt-Dokumente I», en Musik-Konzepte. München: text + kritik, 1999; R. Stephan y otros (eds.), Von Kranichstein zur Gegenwart. 50 Jahre Darmstädter. Beiträge zur Neuen Musik. Stuttgart: Daco, 1996 y G. Borio, y H. Danuser (eds.), Im Zenit der Moderne. Die Internationalen Ferienkurse für Neue Musik Darmstadt 1946-1966. Geschichte und Dokumentation. 4 vols. Freiburg: Rombach, 1997. Para un panorama más general sobre la música de postguerra, véanse H. Vogt, Neue Musik seit 1945. Stuttgart: Philipp Reclam jun., 1972 y U. Dibelius, Moderne Musik nach 1945. München: Piper, 1998.

${ }^{5}$ Véase R. Tiedemann, «Nur ein Gast in der Tafelrunde. Adorno in Kranichstein und Darmstadt 19501966», en Theodor W. Adorno Archiv (eds.), Frankfuter Adorno Blätter VII. München: text + kritik, 2001, pp. 177-185.

${ }^{6}$ De estas conferencias no ha quedado ningún registro escrito o grabado.

${ }^{7}$ Véase T. W. Adorno, «Dificultades. Al componer», op. cit., p. 289 [traducción ligeramente modificada por el autor]. El modus operandi de este curso, del cual no se ha conservado otro documento, fue descripto por Adorno en una conversación posterior mantenida con Heinz-Klauz Metzger. Además allí se refiere a la no muy buena impresión que le habían causado tanto la obra de Goeyvaerts como también una
} 
expuso también una serie de conferencias referidas a Webern y a la relación entre música, sociedad y técnica. ${ }^{8}$ Luego de dos años de ausencia por compromisos académicos contraídos en EEUU, retomó las colaboraciones en Darmstadt y brindó, junto a sus amigos Eduard Steuermann y Rudolf Kolisch, seis seminarios sobre Nueva música e interpretación. De estos últimos se han conservado las notas y palabras claves utilizadas como guías de clase. En estas notas ya aparecían remarcados los síntomas negativos de una tendencia que Adorno denunciaría teóricamente más tarde y que provocaría el enardecimiento de los jóvenes defensores de la música serialista. En efecto, Adorno condensaba en esas notas por lo menos dos de los puntos centrales que afectaban la médula de las tentativas musicales de aquéllos: por un lado, recalcaba los riesgos que corría la música técnicamente más avanzada si se la convertía en una mera cuestión de camarillas especializadas; y, por otro, indicaba la amenaza implícita en la máxima racionalización musical, sobre todo si no conducía a darle una nueva luz a la sustancia crítica de la tradición musical misma. ${ }^{9}$

La articulación teórica más elaborada de estas observaciones críticas fue presentada en la conferencia radial «El envejecimiento de la nueva música», dictada en abril de 1954 en la ciudad de Stuttgart, ${ }^{10}$ En esta conferencia Adorno manifestaría de forma lapidaria ${ }^{11}$ su rechazo a las posiciones estéticas y musicales de esta generación de compositores. Si bien los experimentos con las series de los más jóvenes se presentaban como superadores de los procedimientos schönberguianos, a juicio de Adorno ellos no habían logrado ir más allá de los problemas histórico-compositivos que ya habían sido asumidos de un modo extremo, aunque no resueltos, por el mismo Schönberg. Apoyándose sólo en algunas piezas de las innovaciones de los serialistas existentes en ese momento, ${ }^{12}$ Adorno sostenía que, en las dúctiles manos de éstos, la técnica dodecafónica se había convertido, según una tendencia anticipada en La filosofía de la nueva música, ${ }^{13}$ en un recetario acabado y preformado de producción musical. Esto se advertía principalmente en la disolución de la tensión interna, existente todavía en Schönberg, entre las convenciones musicales heredadas de la tradición y la intervención responsable de la subjetividad en el acto creador. El referente explícito sobre el que recaía la crítica era Pierre Boulez, pero también se aludía a Luciano Berio, Karel Goeyvaerts, Gottrieg König y a obras tempranas de Karlheinz Stockhausen. Según Adorno, «él [Boulez] y sus partidarios pretenden eliminar, junto a los restos del idioma

pieza de Berio. $C f$. H.-K. Metzger, «Disput zwischen Theodor W. Adorno und Heinz-Klaus Metzger (1957)», en R. Riehn (ed.), Musik wozu. Literatur zu Noten. Frankfurt am Main: Suhrkamp, 1980, p. 96.

${ }^{8}$ Estas conferencias luego fueron modificadas y publicadas como ensayos en el libro Figuras Sonoras. Véase T. W. Adorno, «Anton von Webern» y «Música y técnica», en Figuras Sonoras. Escritos musicales I, Obra completa 16, tr. A. Gómez y A. Brotons. Madrid, Akal, 2006, pp. 87-98 y pp. 233-252, respectivamente.

${ }^{9}$ Estas notas están ahora publicadas en R. Tiedemann, op. cit., pp. 178 y sig.

${ }^{10}$ La posición defendida por Adorno en esta conferencia causó un profundo impacto en el movimiento serialista. Véase H.-K. Metzger, «Das Ende der Musikgeschichte», op. cit. En 1957, el mismo Metzger respondió, en nombre de los jóvenes serialistas, a las críticas de Adorno; sobre esto, véase H.-K. Metzger, Heinz-Klaus, «Das Altern der Philosophie der Neue Musik (1957)», en R. Riehn (ed.), op. cit., pp. 113128. Para un análisis detallado de la disputa entre Metzger y Adorno, véase W. Konold, "AdornoMetzger. Rückblick auf eine Kontroverse», en H.-K. Jungheirich, (ed.), Nicht versöhnt. Musikästhetik nach Adorno. Kassel/Basel/London/New York: Bärenreiter, 1987, pp. 91-110.

${ }^{11}$ Sobre las implicancias negativas de una crítica poco concesiva como la de Adorno a las producciones más vanguardistas de la época, véase H.-K. Metzger, «Disput zwischen Theodor W. Adorno und HeinzKlaus Metzger (1957)», op. cit., pp. 93 ss.

12 Adorno reconocería ante Metzger que antes de escribir su conferencia no había tenido acceso a las obras más importantes de estos compositores, sobre todo a la de Boulez y Stockhausen. Véase, ibid, p. 95. ${ }^{13}$ Véase T. W. Adorno, «Noticia», en Filosofia de la nueva música, Obra completa 12, tr. A. Brotons. Madrid: Akal, 2003, p. 191. 
musical tradicional, todo tipo de libertad compositiva como igualmente arbitraria: de hecho, toda emoción del sujeto en la música es al mismo tiempo una emoción del lenguaje musical». ${ }^{14}$

Con ello, proseguía Adorno, el desarrollo de la nueva música estaba mostrando determinados síntomas de estancamiento, percibidos tanto en el trato acrítico con la tradición como en la posición de la subjetividad en la composición musical. Este tipo de rigidez permitía escamotear un conflicto irresuelto en la tradición musical moderna, pero no enfrentarlo verdaderamente. Es decir, los serialistas no cargaban sobre sí con el peso de la tensión entre el acto subjetivo de componer -que debía decidir reflexivamente sobre todos los elementos musicales sin contar ya con ninguno como apoyo- y un deteriorado lenguaje musical tradicional -al que ya no se podía apelar de un modo evidente, pero que, sin embargo, resurgía transformado en los impulsos subjetivos de la composición. ${ }^{15} \mathrm{Al}$ evadir dicha tensión, los aparentes progresos de la nueva música asumían, según Adorno, un carácter estático. El punto sensible para toda la filosofía de la música de Adorno era que, de ese modo, se desatendían las insoslayables implicancias de la dimensión temporal en la música, su rasgo relacional, cuyo desarrollo dialéctico había sido llevado a su más fecunda y crítica expresión histórica en la recapitulación beethoveniana. ${ }^{16}$ «Los constructivistas puntuales [...] ignoran que las relaciones temporales se imponen frente a su propia voluntad y que éstas confieren a lo que en el papel aparece como idéntico un valor completamente diverso». ${ }^{17}$

Desatendiendo la dimensión temporal, ellos se veían expuestos, contra sus deseos, a contradicciones mayores. Adorno encontraba que las nuevas generaciones recaían en una nueva modalidad de fetichización musical y que, precisamente por la pretensión de maximizar la racionalización del material musical, introducían, de una manera paradójica, un rasgo regresivo que entumecía el despliegue de lo no cercenado, cuyo anhelo había definido los esfuerzos de la música de vanguardia. Ese anhelo defraudado se refería tanto a la liberación del sujeto de la coerción de la gramática musical convencional, como también a la de la música misma. Dos meses más tarde de aquella polémica ponencia, Adorno escribía a su amigo Kolisch, otro frecuentador de las tertulias en Darmstadt: «Tu notarás que la oposición en Kranichstein sale menos de los reaccionarios que de personas furiosas del dodecafonismo al estilo de Boulez, los cuales ahora realmente desearían suprimir la música en favor de la más tozuda racionalización». ${ }^{18}$

Para argumentar contra el extravío al que conducía esta radicalización del dominio racional de los materiales, Adorno apelaba a una idea benjaminiana que lo había acompañado desde sus primeros escritos. Cuestionando el desarrollo marcado en extremo por la música puntillista, Adorno afirmaba que el material musical no podía significar desde su pura inmediatez, sino que él sólo podía llegar a tener sentido desde

\footnotetext{
${ }^{14}$ T. W. Adorno, «El envejecimiento de la nueva música», en Disonancias, Obra completa 14, tr. G. Menéndez Torrellas. Madrid: Akal, 2009, p. 151.

15 Para un tratamiento más amplio, véase J. Maiso Blasco, «Modernidad como desmitologización. Theodor W. Adorno y la verdad en el arte como praxis artística y teoría estética», en A. Notario Ruiz (coord.), Contrapuntos estéticos. Salamanca: Ediciones Universidad de Salamanca, 2005, pp. 87-98.

16 «En tanto en cuanto la música trascurre esencialmente en el tiempo, es dinámica hasta el punto de que lo idéntico se vuelve no idéntico en el transcurso, al igual que, a la inversa, lo no idéntico, como por ejemplo una re-exposición abreviada, puede convertirse en idéntico». T. W. Adorno, «El envejecimiento de la nueva música», op. cit., pp. 151 ss. El tema es retomado luego en T. W. Adorno, «La forma en la nueva música», en Escritos musicales III, Obra completa 16, op. cit., p. 622.

${ }^{17}$ T. W. Adorno, «El envejecimiento de la nueva música», op. cit., p 152.

${ }^{18}$ Carta a Rudolf Kolisch del 14.06.1954, citada en R. Tiedemann, loc. cit., p. 180.
} 
las novedosas «constelaciones» en las que se ubicaban los elementos heredados y luego negados por medio de la operación constructiva en la obra de arte individual. ${ }^{19} \mathrm{Si}$ se prescindía hasta del último resabio del trabajo crítico con el lenguaje de las convenciones musicales heredadas, se desmoronaba la posibilidad de comprender las mediaciones que hacían posible la audición correcta del significado del acontecimiento musical, la captación de su coherencia estética. Esto encerraba una dificultad inevitable para el desarrollo de la nueva música, ya que el trabajo consciente debía partir de la tematización de todos los parámetros que instaurasen un sentido musical, pero sin poder contar para ello ya con ninguno como apoyo fijo. Por este motivo, el sentido musical no era susceptible de definiciones, sino más bien concebible cada vez a través de la confrontación activa con la estructura de la obra singular. Como ha destacado ClausSteffen Mahnkopf, toda la filosofía de la música adorniana, y por consiguiente su crítica al serialismo, pivoteaba en torno a esta dialéctica entre la no identidad de la temporalidad, que introduce lo cualitativamente nuevo, y la identidad del contexto material en la obra musical. ${ }^{20}$

La revocación indeterminada de todo sentido a la que conducía una racionalidad integral no había acaecido ni siquiera en el umbral de la máxima fragmentación en las obras de Schönberg. Por el contrario, el abordaje del dodecafonismo del músico vienés, según había sido planteado por Adorno en Filosofía de la nueva música, permitía interpretar la falta de la coherencia estética como constitutiva de sus constelaciones tecnológico-musicales, y no como erradicación abstracta de la coherencia misma. Pues lo que estaba en juego allí era el trabajo de la negación determinada del sentido. Este trabajo negativo transformaba el sentido en rebelión contra sí mismo en una doble dirección: contra el sentido heredado de la obra de arte orgánica y contra el puro sentido estético en tanto que ahora se tornaba impugnación de una realidad social desquiciada. En palabras de Adorno, «[...] esto comporta no meramente la crítica al dodecafonismo de que la obra de arte total, enteramente construida, es decir, enteramente coherente, entra en conflicto con su propia idea, sino que, en virtud de la incipiente falta de sentido, se manifiesta la cerrazón inmanente de la obra. Ésta consiste en, precisamente, la coherencia constitutiva del sentido. Tras su eliminación la música se convierte en protesta». ${ }^{21}$

En concreto, la preocupación de Adorno era que si se purificaba a la música de los últimos vestigios de sentido, ya no se podría reconocer ningún criterio para diferenciarla de una vacía esquematización técnica o del mero ruido inarticulado. Y lo que Adorno observaba era que la desaparición del carácter doblemente determinado de la negación del sentido era un estigma común en el círculo de Darmstadt. De hecho, la pretensión de romper de raíz tanto con el horizonte de la tradición como con la propia subjetividad, en cuanto portadores de sentido musical, y elaborar una música inexpresiva, constituía, además de ciertas marcas antropológicas comunes, ${ }^{22}$ uno de los

\footnotetext{
${ }^{19}$ T. W. Adorno, «El envejecimiento de la nueva música», op. cit., p. 153.

${ }^{20}$ Véase C.-S. Mahnkopf, «Adornos Kritik der Neueren Musik», en R. Klein y C.-S. Mahnkopf (eds.), Mit den Ohren denken. Adornos Philosophie der Musik, Frankfurt am Main: Suhrkamp, 1998, p. 257. En las dos páginas siguientes de su artículo, Mahnkopf describe el modo en que, en la conferencia Forma en la nueva música, Adorno concibe la consumación concreta de esta dialéctica en los intentos (ahora elogiados) de Boulez en Pli selon Pli y de Stockhausen en Gruppen.

${ }^{21}$ T. W. Adorno, Filosofía de la nueva música, op. cit., p. 114.

22 «La juventud ya no se atreve a ser joven. El miedo y el sufrimiento han crecido extremadamente y no se dejan ya dominar por la psique de cada individuo. Esto obliga a la represión y ésta, y no el positivismo de un estado aparentemente superior de vergüenza y autodominio, es la que se oculta tras la aversión hacia toda expresión, la cual es idéntica al sufrimiento». T. W. Adorno, «El envejecimiento de la nueva música», op. cit., p. 156.
} 
principales motivos al que recurría Adorno para cuestionar al mismo tiempo a un grupo de compositores tan disímiles como los que rondaron los seminarios en Darmstadt. Por ello que no consideraba un mero hecho circunstancial la atracción de los jóvenes vanguardistas europeos por compositores norteamericanos como John Cage, quien se relacionaba de un modo oblicuo con el contexto de la tradición musical europea. ${ }^{23}$ Sea como fuere la gravitación entre los músicos, en esa convergencia Adorno notaba que, tanto unos como otros, no sólo desatendían el devenir histórico del material musical y el componente de mediación colectiva que allí se sedimentaba, sino que también terminaban destruyendo el sentido musical mismo, sin el cual no se podía experimentar viva y críticamente la ejecución musical. ${ }^{24}$

Con esto, más que desbrozar a la música de la necesidad y la coacción de un estado heterónomo, e introducirla en el reino de libertad prometido por el proceso de organización racional del mundo, los serialistas la sometían a un potencial regresivo de autoridad irracional. Luego de mostrar el debilitamiento de la autoconciencia de las tensiones históricas sedimentadas en el material musical y, especialmente, la pulverización de la tarea del momento subjetivo en el acto configurador, Adorno concluía, de un modo acorde con los resultados de Dialéctica de la Ilustración, que la música desencantada se estaba conduciendo irreflexivamente «hacia estadios primitivos como los que acompañan en la sombra el progreso social». ${ }^{25}$

\section{LA EXONERACIÓN RADICAL DEL SUJETO}

En una conferencia para la radio de Bremen emitida en mayo de 1964, Adorno volvía a observar, contra las llamadas composición integral y electrónica, que quienes se aferraban a ellas propendían a claudicar ante los medios técnicos de composición sin haber llegado a componer en sentido estricto con ellos. ${ }^{26}$ Estas composiciones se resignaban ante las fuerzas de producción objetivas sin haberlas medido en ningún momento con la propia conciencia subjetiva o, dicho de otro modo, sin haber elevado la autorreflexión subjetiva al nivel histórico alcanzado por esas fuerzas en el presente. Esto reflejaba las consecuencias extremas del proceso de exoneración de la subjetividad, el cual contrastaba, según Adorno, con el momento de mayor potencia imaginativa en las obras del Schönberg intermedio y en las juveniles de Berg y Webern. ${ }^{27}$

El proceso de exonerar al sujeto, entendido como predominancia del procedimiento técnico sobre la libertad del oído en la composición, tenía su justificación histórica. ${ }^{28}$ Ella consistía en la necesidad de alivianar las decisiones subjetivas por medio de determinados procedimientos que permitieran enfrentar las dificultades que imponía un material que ya, entrado el siglo XX, apenas se podía dominar con la sola fuerza del compositor individual. De ahí que el surgimiento del dodecafonismo respondiera a la necesidad de una relajación de los laboriosos controles del yo en la composición. Sin embargo, la exigencia de exoneración terminó implantándole coactivamente a la música un sistema serial que se imponía sobre las decisiones individuales. La organización racional de la composición ya no se seguía de los sucesos

\footnotetext{
${ }^{23}$ T. W. Adorno, «Tradición», op. cit., p. 128.

${ }^{24}$ T. W. Adorno, «El envejecimiento de la nueva música», op. cit., p. 156.

${ }^{25}$ T. W. Adorno, «Opinión pública, crítica», en Introducción a la sociología de la música, Obra completa

14, op. cit., p. 345.

${ }^{26}$ Véase T. W. Adorno, «Dificultades. Al componer», en Impromptus, op. cit., p. 279.

${ }^{27}$ Ibid., p. 285.

${ }^{28}$ Agradezco las observaciones de F. Monjeau sobre este punto.
} 
musicales. El orden de lo que acontecía era impregnado desde el exterior, lo cual generaba incongruencias con el impulso moderno que alentaba a la máxima constitución racional sin apelar a nada heterónomo.

La necesidad de resolución de estas incongruencias guió gran parte del afán de las principales obras seriales en el seno de Darmstadt. Nada que remitiera al enmohecido lenguaje de la tonalidad debía introducirse en la composición. Todos los acontecimientos musicales debían estar completamente determinados. La obediencia del compositor a lo contenido en la serie lo eximía por tanto de preocuparse en cada caso por la viva consumación auditiva, por la pura libertad del oído atento en su cruce con los sucesos de la música. Pero la absolutización del procedimiento serial a todas las dimensiones compositivas arrastraba un serio problema, el cual había sido formulado por Adorno a propósito de la Sonata para dos pianos op. I de Goeyvaerts: «Si no se tratara, en serio, más que de componer exhaustivamente lo que en una serie tal hay, entonces se podría -el chiste es tan malo como la realidad-componer mejor con la ayuda de una computadora electrónica que molestando a un compositor. La ayuda que éste recibe le cuesta el cuello. Se somete a unas leyes que le son ajenas y que le es difícil cumplir. Pero la música de ahí resultante se convierte en algo sordo y huero». ${ }^{29}$

En la crítica a la reducción de la praxis compositiva a pura técnica, Adorno subrayaba que de esa forma se agudizaba la tendencia hacia la polarización abstracta entre las reacciones del sujeto compositivo y el desarrollo de la objetividad musical. Si bien esto ocurría en el interior de la obra, la desproporción entre el avance de las fuerzas técnicas de producción y la regresión subjetiva en la praxis musical no era ajena a la tendencia social más general. Las tesis filosóficas y sociales desarrolladas por Adorno y Max Horkheimer, en especial aquellas referidas al detrimento de la reflexión sobre los fines de las acciones humanas y al consiguiente reinado de los medios, ${ }^{30}$ calaban también en las fibras más íntimas de aquellas producciones estrictamente musicales que parecían estar a salvo, por su constitución intransigente y aislada, de la presión del todo social.

Con la radicalización de la exoneración de la subjetividad y la ambición concomitante por la depuración técnica, los jóvenes compositores disolvían el aspecto irreductible de la conciencia subjetiva en la relación entre sujeto y objeto, y elevaban a la técnica a un fin que remitía sólo a sí mismo. Sin embargo, según Adorno, dicha exoneración no carecía de legítimas razones. La liquidación absoluta de cualquier rastro de contingencia subjetiva tenía su justificación en la esperanza de que, en el debilitamiento de la subjetividad, pudiera hablar el puro sonido en vez del yo psicológico y, de ese modo, el sujeto quede liberado de su voluntad posesiva y opresora. También Adorno veía en el intento de abandonar los dictados de la imaginación subjetiva, dejando con ello, por ejemplo, que el principio constructivo fuese guiado por el mero azar, una respuesta consciente a la pérdida de poder del sujeto provocada por la tecnologización total de la sociedad burguesa. ${ }^{31}$ Pero al crear en su lugar, en forma de programa, relaciones entre sonidos timoneados sólo por proporciones matemáticas, presuntamente objetivas, se desatendía el hecho de que era el mismo sujeto quien en un primer momento extraía el sentido del material musical. ${ }^{32}$ Con ello se degradaba el

\footnotetext{
${ }^{29}$ Ibid., p. 289.

${ }^{30}$ Véase M. Horkheimer, «Medios y fines», en Crítica de la razón instrumental, tr. H. Murena y D. Vogelmann, Buenos Aires: Sur, 1973, pp. 15-68; véase también, T. W. Adorno y M. Horkheimer, Dialéctica de la Ilustración. Fragmentos Filosóficos, Obra completa 3, tr. J. Chamorro Mielke. Madrid: Akal, 2007.

${ }^{31}$ Véase especialmente T. W. Adorno, Ästhetische Theorie. G. Adorno y R. Tiedemann (eds.), Frankfurt am Main: Suhrkamp, 1973, p. 43.

${ }^{32}$ Véase T. W. Adorno, «El envejecimiento de la nueva música», op. cit., p. 154.
} 
momento expresivo del lenguaje musical, instancia que recordaba la naturaleza reprimida en el sujeto. De ahí que Adorno encontrara en esa rebelión inmediata de los jóvenes contra todo sentido musical una negación abstracta que conectaba, subterráneamente, con una corriente arcaizante operante ya en el neoclasicismo alemán: «Sus tendencias se han comparado con las aspiraciones cibernéticas de la ciencia y de la automatización industrial; el decurso es tan autónomo que, según la expresión de E. I. Kahn, se perfila una especie de música robótica». ${ }^{33}$

El problema era que la subjetividad extirpada en aras de la más pura facticidad retornaba, contra las pretensiones de la máxima racionalización, como ciega dominación subjetiva de la naturaleza, como reflejo de la coerción de la necesidad natural. Esto atentaba contra el momento de espontaneidad y libertad del individuo, desencadenado por la ilustración, en su relación con las resistencias del material al que se enfrentaba. En este marco, Adorno no entendía por libertad la compulsión caprichosa y vacía del sujeto soberano que toma el mundo circundante de un modo indeterminado como pretexto para el conocimiento de su propia producción. Por el contrario, concebía la libertad como una praxis de exploración específica, por la cual el impulso subjetivo, él mismo un producto mediado históricamente, se relacionaba de un modo novedoso con la objetividad musical, es decir, con el idioma y las fuerzas técnicas de producción musicales. Esa relación no tenía nada de arbitrario. Pues era el máximo desarrollo alcanzado por estas fuerzas el que condicionaba al compositor a "prestar oído, más que [a] producir». ${ }^{34}$ "Con cada compás la técnica en su totalidad exige de él que le haga justicia y le dé la única respuesta correcta que ella admite en cada instante». ${ }^{35}$

Esta línea de reflexión, que vinculaba reflexivamente a la composición en todo momento con la tradición, aparecía ya en las inquietudes que Adorno planteaba a sus oyentes en los seminarios de 1954. Allí Adorno sugería que lo realmente importante era, más que depurar a la composición de todo rudimento técnico del pasado, aquello que se podría aprehender de nuevo -esto es, críticamente- de la música tradicional a través de las ejecuciones de la música actual. ${ }^{36}$ Sin afrontar esta ineludible tensión dialéctica con la tradición o, más específicamente, con la tradicional constitución del sentido musical, quedaban agotaban las posibilidades de toda experiencia con nuevos sonidos y, junto a esto, se enturbiaba el cumplimiento del objetivo de los esfuerzos llevados a cabo en Darmastadt de liberar capas cada vez más amplias del material musical.

La problemática relación entre la disolución del momento subjetivo-individual y la tendencia a la fetichización del material musical, Adorno la hallaba prefigurada en las últimas obras de Anton von Webern, quien había sido adoptado por la joven generación como su mentor musical. En una ponencia radial de 1959, elaborada en base a las notas de un seminario de 1951 en Darmstadt y luego publicada en la revista Merkur, Adorno verificaba una línea de continuidad entre el modo en que se anunciaba en las composiciones del Webern tardío la pérdida de la tensión interna y el privilegio dado por sus sucesores al principio de construcción total: «[...] el ideal de componer sin violencia -y ésa es la última de las paradojas de Webern- desencadena esa evolución de su época tardía que reforzó a los seguidores en el esfuerzo por dominar totalmente el material musical. La completa no violencia se convierte en completa violencia [...] Sería indigno de él, sencillamente ignoraría su enfática pretensión, si se negara que las últimas obras, frente a la libertad de lo necesario en las tempranas, hacen sospechar algo

\footnotetext{
${ }^{33}$ T. W. Adorno, «La nueva música hoy», en Escritos musicales V, Obra completa 18, tr. A. Gómez y A. Brotons. Madrid: Akal, 2011, p. 137.

${ }^{34}$ T. W. Adorno, «Sobre algunos trabajos de Arnold Schönberg», op. cit., pp. 353 ss.

${ }^{35}$ T. W. Adorno, Filosofia de la nueva música, op. cit., p. 41.

${ }^{36}$ Véase R. Tiedemann, loc. cit., pp. 178 ss.
} 
alienado, un fetichismo del material, comparable en todo caso con la obra tardía de Kandinsky o incluso de Klee». ${ }^{37}$

Lo que se avizoraba como paradójico en Webern, se tornaba flagrante en sus sucesores -es decir, la disolución de la vital acción responsable del sujeto en la producción artística, y la reducción de lo compuesto a pura técnica. Como se mencionó anteriormente, Adorno reconocía el momento de verdad de este desarrollo. De hecho, las obras de estos compositores eran una expresión históricamente necesaria tanto de la cosificación general, como de la anulación del individuo en las sociedades postindustriales. Ellas señalaban la miseria del estado de cosas. Sin ese señalamiento, la negatividad del mundo se volatilizaría - sin ser superada- en el engaño de la armonía ya lograda suministrado por la industria de la cultura y el aparato administrativoburocrático. No obstante, la concesión llegaba hasta ese punto. Pues en sus intenciones musicales, los seguidores de Webern terminaban anulando la historicidad inmanente del proceso de constitución de la objetividad musical que ponía en juego lo cualitativamente nuevo, lo abierto: «Si la Nueva Música ha de llevar con toda certeza al lenguaje musical y al material musical a la congruencia plena, tanto menos ha de ser buscada dicha congruencia en el hecho de eliminar sencillamente el lenguaje musical y abandonar a sí mismo al descalificado resto sobrante, o bien, en lugar de penetrar en él, recubrirlo con meros esquemas de ordenamiento [...] El impulso de nivelación y cuantificación parece más poderoso en la música electrónica que el objetivo de un desenfrenamiento cualitativo». ${ }^{38}$

Se podría decir entonces que Adorno veía en estas tentativas de máxima radicalidad la continuidad del fetichismo del material musical, en donde el sujeto dominador quedaba despojado de toda huella de humanidad. Aunque lo inhumano allí contenía algo verdadero. Pues estas obras procuraban, desde su comportamiento estético, una crítica de la ideologización de lo humano en el arte, en tanto revelaban con crudeza aquello en lo que el hombre realmente se había convertido: un fungible, un ser para otro. Sin embargo, al deshacerse llanamente de toda subjetividad, de todo momento expresivo, se revocaba también esa autoconciencia, lograda a partir de Schönberg, ${ }^{39}$ de las contradicciones inmanentes de la obra de arte entre el impulso mimético-expresivo y el principio racional dador de forma. En definitiva, concebir lo que era artísticamente posible en un período dado era, para Adorno, pensarlo en la dialéctica de esos momentos no reconciliados, pero sin renunciar al «horizonte de su reconciliación posible». ${ }^{40}$ Lo cual constituía, a su vez, una de las antinomias centrales de la estética adorniana, puesto que la obra de arte sería auténtica sólo si lograba representar a la naturaleza reprimida por medio de lo que el mismo arte auténtico había producido históricamente a través del progresivo dominio racional de la naturaleza. Y el progresivo dominio racional no había dejado de ser, para el frankfurtiano, más que una historia de violencia.

\section{LO POLÍTICO EN LA MÚSICA DESENCANTADA}

Es verdad que Adorno divisaba ya en la década de 1950, particularmente en Boulez y Stockhausen, atisbos concretos de resistencia contra la composición

\footnotetext{
${ }^{37}$ T. W. Adorno, «Anton von Webern», op. cit., pp. 124 ss.

${ }^{38} \mathrm{~T}$. W. Adorno, «El envejecimiento de la nueva música», op. cit., pp. 180 ss.

${ }^{39}$ Véase T. W. Adorno, «Dificultades. En la comprensión de la nueva música», en Impromptus, op. cit., p. 298.

${ }^{40}$ T. W. Adorno, Ästhetische Theorie, op. cit., p. 285.
} 
absoluta. ${ }^{41}$ También es cierto que supo captar de un modo más adecuado a la obras más logradas del serialismo y del postserialismo algunas deficiencias de su propio posicionamiento, y que mitigó por ello el reproche de envejecimiento que había lanzado anteriormente contra los más jóvenes -en este contexto ahora Adorno celebraba a Zeitmaße, Gruppen, Kontakte y Carré de Stockhausen, a Le marteau sans maître, la Segunda y Tercera sonata para piano y la Sonatina para flauta de Boulez, como así también al Concierto para piano de Cage. Esta rectificación en el juicio en alguna medida mostraba la incómoda posición en que se encontraba alguien que, apegado a la tradición musical de la segunda escuela de Viena, llegaba a reconocer la modernidad de las nuevas generaciones, las cuales, a su vez, experimentaban a aquella tradición como algo ya demasiado rancio.

El intento de superar esa incomodidad se cristalizó en la conferencia de 1961 «Vers une musique informelle». ${ }^{42}$ En ella, Adorno no sólo registraba con beneplácito el proceso de autoilustración desencadenado en el interior del serialismo, ${ }^{43}$ sino que también intentaba avanzar en el proyecto de delinear la idea de lo que sería una musique informelle. Ésta debería constituir, en la articulación completa de todas sus dimensiones compositivas, una «imagen de la libertad». ${ }^{44}$ Según este texto programático, la música venidera tendría que ser capaz tanto de reactivar la reacción involuntaria del oído compositivo, lo que Adorno llamaba «espontaneidad», pero revocando su potencial violencia, como también de enfrentar sin paliativos la posibilidad real y extrema del endurecimiento total. ${ }^{45}$ En suma, esta tentativa ya no se movía en el registro crítico de la conferencia de Stuttgart, sino que, por el contrario, implicaba el reconocimiento de los nuevos desarrollos musicales, marcados ahora por la impronta autocrítica del círculo de vanguardia que habían frecuentado las sesiones de Darmstadt.

La interpelación de Adorno a los jóvenes compositores, con los cuales se reencontraba luego de un prolongado distanciamiento, ${ }^{46}$ pretendía irradiar en ellos la exigencia de cargar sobre sí con la experiencia de lo extremo, de lo no preformado, de aquello que era fagocitado una y otra vez por el aparato de administración. Sin embargo, a pesar de este acercamiento de posiciones, que no sin un gesto de vanidad Adorno atribuía a su anterior diagnosis, ${ }^{47}$ la valoración con respecto a ellos continuó

\footnotetext{
${ }^{41}$ Véase T. W. Adorno, «Criterios de la nueva música», en Figuras sonoras, op. cit., p. 205; también véase T. W. Adorno, «La nueva música hoy», op. cit., p. 138 ss.

${ }^{42}$ T. W. Adorno, „Vers une musique informelle», en Quasi una fantasia, Obra completa 16, op. cit., pp. 503-549. La importancia capital de esta conferencia para el conjunto de la obra estético-musical de Adorno ha sido enfatizada, desde una perspectiva de técnica compositiva, por Claus-Steffen Mahnkopf: «Vers une musique informelle es la metateoría de la filosofía de la nueva música, cuyo diagnóstico de la racionalización en este sentido anticipaba los problemas del serialismo, en tanto que éste generaliza la estructura de pensamiento de las series dodecafónicas, y es un texto filosófico fundamental para la totalidad pensamiento de Adorno, una pieza prima philosophia in musicis, que busca cerciorarse de las categorías básicas -principalmente, las del tiempo, forma, material, sujeto, construcción, técnica de composición, lógica musical, expresión y sentido». C.-S. Mahnkopf, loc. cit., p. 259 ss. Para una lectura retrospectiva de la conferencia desde la perspectiva de uno de los principales protagonistas, véase P. Boulez, «L'informulé», Revue d'Esthétique, 8 (1985), pp. 25-29.

${ }^{43}$ Véase T. W. Adorno, op. cit., p. 506.

44 «En una musique informelle cabría superar positivamente el hoy deformado momento de racionalización. Sólo lo totalmente articulado desde el punto de vista artístico es la imagen de algo no mutilado y por tanto de la libertad». Ibid., p. 546.

45 Ibid., p. 547.

${ }^{46}$ Sobre la inesperada interrupción de la colaboración de Adorno en los cursos de Darmstadt se puede consultar R. Tiedemann, op. cit. pp. 183 ss.

${ }^{47}$ T. W. Adorno, «Dificultades. Al componer», op. cit., p. 289.
} 
siendo demasiado vacilante. ${ }^{48}$ Y lo era porque, si bien el filósofo de Frankfurt había reconocido en las nuevas manifestaciones un momento liberador en la tendencia a la máxima agudización de la racionalidad musical -como ejemplos predilectos Adorno ponía a Le marteau sans maître y a Zeitmaße ${ }^{49}$-, también seguía convencido que no había salvación posible si se erradicaba de la composición misma el resquicio de la ya débil subjetividad latente en la música más avanzada. Y de esta objeción, desde la perspectiva adorniana, seguía sin librarse la mayor parte de las composiciones serialistas y postserialistas. ${ }^{50}$

Esta preocupación se manifestaba en el planteamiento que presentó Adorno en su penúltima intervención en Darmstadt, centrada en el problema de la forma y dedicada sugestivamente a Pierre Boulez. ${ }^{51} \mathrm{Al}$ final de la conferencia, y a tono con su idea de una musique informelle, Adorno exhortaba a sus oyentes sobre la necesidad de restituir críticamente la noción de sentido formal cuestionada dentro del círculo de los serialistas. En la reivindicación de esta noción, Adorno extendía la crítica contra el serialismo, condenando todo modo de componer que eliminara las tensiones entre el sujeto, que debía producir ya todo desde sí mismo, y un lenguaje musical atrofiado. El concepto de «sentido formal» trazaba entonces una tarea que abogaba por la posibilidad de un componer «rizomático» ${ }^{52}$, ni impuesto desde arriba, ni tampoco sustentado en una nueva idolatría de la espontaneidad creativa: ${ }^{53}$ «[...] seguir con el oído la música adonde ésta de por sí quiera ir; tan lejos de la voluntad impuesta, de la arquitectura impuesta, como de las necesidades ajenas a ella en las que la mayoría de las veces se atrinchera el obcecado arbitrio subjetivo [...] Pero para ello ha menester la máxima tensión subjetiva. El oído especulativo es el único órgano de la objetividad no garantizada, negativamente la instancia de protección contra su falsificación». ${ }^{54}$

El cuestionamiento de Adorno a los serialistas no se limitaba al problema técnico-musical operante en la forma, sino que, por medio de la exposición de problemas estéticos, él intentaba además arrojar luz sobre cómo los procedimientos técnicos contenían implicancias sociales y políticas. Teniendo en cuenta esto, la insatisfacción adorniana con los más jóvenes se basaba en la apuesta del filósofo por un arte que fuera autónomo y, a su vez, crítico del estado del estado de cosas existente. El arte auténtico tenía además la exigencia tanto de hacerse cargo del horror de lo sucedido, como de mantener abiertas las promesas de una libertad y felicidad posible para todos. El arte moderno radical se constituía así en testimonio de lo históricamente negado, sacrificado o neutralizado por la sociedad que lo engendraba, al mismo tiempo en que se rebelaba contra la ciega reproducción de la misma. ${ }^{55} \mathrm{Y}$ todo esto en el terreno estrictamente técnico-compositivo. En otros términos, el reclamo de Adorno se refería a

\footnotetext{
${ }^{48}$ Cf. F. Monjeau, La invención musical. Ideas de historia, forma y representación. Buenos Aires: Paidós, 2004, p. 99.

${ }^{49}$ T. W. Adorno, «Prefacio a la tercera edición», en Disonancias, op. cit., p. 12.

${ }^{50} \mathrm{Cf}$. T. W. Adorno, «Dificultades. En la comprensión de la nueva música», op. cit., p. 310.

51 T. W. Adorno, «La forma en la nueva música», op. cit., pp. 617-636. La participación de Adorno en los Cursos Internacionales de Verano de Darmstadt culminaría en septiembre de 1966 con la lección «Funktion der Farbe in der Musik», actualmente publicada en H.-K. Metzger y R. Riehn (eds.), «Sonderband Darmstadt-Dokumente I», op. cit., pp. 263-312.

${ }^{52}$ C-S. Mahnkopf, loc. cit., p. 258.

${ }^{53}$ Véase F. Monjeau, op. cit., p. 95.

${ }^{54}$ T. W. Adorno, «La forma en la nueva música», op. cit., pp. 635 y sig.

${ }^{55}$ En este contexto, la idea de conservación refiere a la dialéctica de la tradición y de lo nuevo explorada por Adorno ya en su Filosofía de la nueva música. Allí advertía contra el otro extremo de la falsa conciencia musical, es decir, contra la restauración antojadiza de lo pasado, que él atribuía a Stravinsky y a su entorno: «La conservación arbitraria de lo superado pone en peligro lo que quiere conservar y choca con mala conciencia contra lo nuevo». T.W. Adorno, Filosofía de la nueva música, op. cit., p.16.
} 
la misión insobornable de las obras de arte auténticas y radicales de configurar, en el campo de sus tensiones internas entre los momentos constructivos y racionales y los miméticos y expresivos, tanto la experiencia del sufrimiento como la esperanza endeble -más aún consumada la casi completa adaptación de todos los sujetos a un sistema que Adorno consideraba falso- en una conciliación no forzada entre todo lo diferenciado: «Cuanto más puro y menos atenuado se aprehenda el antagonismo, cuanto más profundamente se halle configurado, la música será menos ideológica y más cabal en tanto que conciencia objetiva. Si se objetara que la configuración en sí es ya conciliación y por ende ideología, se pondría con ello el dedo en la llaga. Pero en tal medida la configuración hace justicia a la realidad como totalidad organizada y diferenciada tiene su idea en la configuración y pone de manifiesto que, pese a todos los sacrificios y miserias, aún subsiste la vida de la humanidad». ${ }^{56}$

Así, el problema estético de la configuración en los «juegos malabares con las series» ${ }^{57}$ remitía, transversalmente, a una esfera extraestética, a la política, ya que Adorno advertía en los jóvenes compositores una propensión, latente en el trabajo con el material musical, hacia una demasiada estrecha connivencia con lo establecido. Y así lo expresaba en un texto basado en sus lecciones de sociología de la música: «El núcleo de la diferencia sociológica entre la nueva música en torno a 1960 y aquella en torno a 1920 es probablemente la resignación política, reflejo de aquella concentración del poder social que o bien prohíbe la acción del impotente, o bien la transforma en la medida de otro poder. El sentimiento de que nada puede hacerse ha asaltado a la música». ${ }^{58}$

De este modo, el sesgo político de la crítica de Adorno a la música desencantada habría que buscarlo en el gesto de resignación que contenían sus propuestas. Pues el serialismo, más que asumir las tensiones internas y fortalecer con su experimentación la negación de lo existente y el recuerdo de lo reprimido -lo cual implicaba que en las obras de arte auténticas hibernaban todavía expectativas de emancipación de todo lo pasado como posibilidades malogradas-, comenzaba a acomodarse, impotente, cada vez más al reificado mundo real.

El énfasis de Adorno por un arte que en su autonomía constituyera un indicio necesario para mantener con vida la posibilidad de una praxis transformadora no distorsionada, se conjugaba con su desconfianza acerca de las alternativas de acción que se manejaban en la esfera social y política. Adorno pensaba que en el mundo completamente administrado toda acción política estricta estaba paralizada o degradada a la categoría de acción calculadora. Todas eran igualmente incapaces de materializar una acción movilizadora opuesta a las relaciones de dominación existentes. Ellas, o caían presa de la instrumentalización reinante o, peor, ayudaban a reforzar su poder opresivo. Ni siquiera las obras más avanzadas podían escapar a la maldición que pesaba sobre la realidad social. En tal sentido, Adorno pretendió encontrar en el arte radical de algunos individuos aislados una justificación política, o, con mayor precisión, un criterio de juicio estético comprometido políticamente. Sin ello, le hubiese quedado poco que le permitiera rebasar el nihilismo extremo al que hubiera conducido de otro modo su escepticismo con respecto a la concreción de la libertad en el mundo reglamentado y sin fisuras: ${ }^{59}$ «El acento en la obra autónoma es él mismo de esencia sociopolítica. La deformación de la verdadera política aquí y ahora, la solidificación de las

\footnotetext{
${ }^{56}$ T. W. Adorno, «Clases y estratos», en Introducción a la sociología de la música, op. cit., p. 252.

${ }^{57}$ T. W. Adorno, «El envejecimiento de la nueva música», op. cit., p. 162.

${ }^{58}$ T. W. Adorno, «Modernidad», en Introducción a la sociología de la música, op. cit., p. 377.

${ }^{59}$ Sobre la idea del fracaso de la política en Adorno, véase S. Schwarzböck, Adorno y lo político. Buenos Aires: Prometeo, 2008.
} 
relaciones, que en ninguna parte parecen estar a punto de derretirse, obligan al espíritu a refugiarse allí donde no tenga necesidad de encanallarse. Mientras que en la actualidad todo lo cultural, incluso las obras íntegras, corre el riesgo de resultar sofocado en el guirigay de la cultura, en el mismo momento sin embargo se encarga a las obras de arte de conservar sin palabras aquello que está obstruido a la política». ${ }^{60}$

En esa actualidad política y cultural estaba inmersa también la nueva música de los compositores de postguerra. Tratar de desmotar ese intrincamiento entre realidad política y social y arte, y captarlo no extrínsecamente, sino en el interior de esas mismas producciones, en su vínculo histórico con el proceso de desmantelamiento de la tradición musical occidental, ocupó gran parte de los esfuerzos de Adorno a su regreso del exilio americano. Al hacerlo, no dejó de advertir que esas obras -aquellas que anhelaban depurar su material de todo elemento indeseado del pasado y de todo componente expresivo- no llegaban a responder a la medida de su propio concepto. Pues ellas tendían a debilitar su potencia negativa. Esta potencia no sólo dotaba a las obras autónomas de su coherencia, en un momento en que esta misma noción estaba en crisis, sino que, al mismo tiempo, su negatividad constituía una de las pocas fuerzas discordantes que todavía latía en el mundo administrado. En 1957, al final de la conferencia Criterios de la nueva música pronunciada en Kranichstein, Adorno reiteraba esta exigencia que justificaba la radicalidad de los hallazgos de los artistas más avanzados: «Al presionar sobre la identidad absoluta en la negación de lo particular y lo universal, la nueva música quiere convertirse en la voz de lo que en aquélla no desaparece, de lo no-idéntico». ${ }^{61}$

El desencantamiento absoluto amenazaba, sin embargo, con extinguir la característica esencial del momento crítico del arte moderno radical, su diferencia respecto de la presión asfixiante de la realidad empírica. ${ }^{62}$ En efecto, Adorno no sólo divisaba en la propensión al envejecimiento de la nueva música un rasgo propio de lo que Max Weber había denominado como la «racionalización progresiva de la música». También veía que, a través de este proceso, en el arte más avanzado estaba operando, con una energía implacable, una sombría tendencia hacia la clausura total de lo existente: «El triunfo del mero ser ser-ahí sobre la mirada de la consciencia que osa resistírsele». ${ }^{63}$ La positividad triunfante inervaba a la nueva música, puesto que con el entumecimiento de la débil fuerza sediciosa del arte contra lo existente se intensificaba un silencioso peligro. En el fondo, ese peligro que acechaba a la nueva música no era otro que la naturalización del hecho, para Adorno siniestro y no sólo desde el punto de vista estético y musical, de que ya nada en el mundo falsamente integrado resultase, al fin y al cabo, disonante con ese mundo.

Esteban Alejandro JuÁRez es Profesor Asistente en la Universidad Nacional de Córdoba y Becario de SeCyT - Universidad Nacional de Córdoba (Argentina)

Linea de investigación:

Estética y Teoría Crítica

\footnotetext{
${ }^{60}$ T. W. Adorno, «Compromiso», en Notas sobre literatura, Obra completa 11, tr. A. Brotons. Madrid: Akal, 2003, p. 413 [Traducción ligeramente modificada por el autor].

${ }^{61}$ T. W. Adorno, «Criterios de la nueva música», op. cit., p. 232.

62 Véase T. W. Adorno, Ästhetische Theorie, op. cit., p. 323.

${ }^{63}$ T. W. Adorno, Filosofia de la nueva música, op. cit., p. 23.
} 
Publicaciones recientes:

(2010) «La afinidad entre arte y filosofía en Adorno», en Representaciones. Revista de Estudios sobre Representaciones en Arte, Ciencia y Filosofia, vol. 6, nº 1, Córdoba, pp. 23-40. ISSN: 1669-8401.

(2012) «Th. W. Adorno: el elogio de la teoría y la impaciencia de la praxis», en Signos Filosóficos, n ${ }^{\circ}$ 27, Universidad Autónoma Metropolitana-Iztapalapa, México D.F., pp. 89-118, ISSN: 1665-1324

Dirección electrónica: juarezeal@hotmail.com 